\title{
RESEARCH
}

Open Access

\section{High-Fidelity simulation-based program improves flow state scale in the perinatal team}

\author{
Mariachiara Martina Strozzi ${ }^{1}$ D, Alessandro Varrica ${ }^{2}$, Micaela Colivicchi $^{1}$, Claudia Pelazzo ${ }^{1}$, Rossana Negri1 $^{1}$ \\ Anna Galante ${ }^{1}$, Patrizia lanniello ${ }^{1}$, Rossella Sterpone ${ }^{3}$, Priscilla Nannini ${ }^{3}$, Daniela Leo ${ }^{3}$, Francesca Mannarino ${ }^{3}$, \\ Manuel Striani ${ }^{4}$, Stefania Montani ${ }^{4}$ and Diego Gazzolo $0^{5,6^{*}}$
}

\begin{abstract}
Background: We aimed to evaluate the degree of realism and involvement, stress management and awareness of performance improvement in practitioners taking part in high fidelity simulation (HFS) training program for delivery room (DR) management, by means of a self-report test such as flow state scale (FSS).

Methods: This is an observational pretest-test study. Between March 2016 and May 2019, fourty-three practitioners (physicians, midwives, nurses) grouped in multidisciplinary teams were admitted to our training High Fidelity Simulation center. In a time-period of 1 month, practitioners attended two HFS courses (model 1, 2) focusing on DR management and resuscitation maneuvers. FSS test was administred the end of M1 and M2 course, respectively.

Results: FSS scale items such as unambiguous feed-back, loss of self consciousness and loss of time reality, merging of action and awareness significantly improved $(P<0.05$, for all) between $\mathrm{M} 1$ and $\mathrm{M} 2$.

Conclusions: The present results showing the high level of practitioner involvement during DR management-based HFS courses support the usefulness of HFS as a trustworthy tool for improving the awareness of practitioner performances and feed-back. The data open the way to the usefulness of FSS as a trustworthy tool for the evaluation of the efficacy of training programs in a multidisciplinary team.
\end{abstract}

Keywords: Simulation based training, Delivery room, Neonatal resuscitation, Flow state scale test

\section{Introduction}

Epidemiological data reported that, at birth, about $10 \%$ of newborns respond during drying and stimulation maneuvers, approximately $3 \%$ initiate respiration after positive-pressure ventilation (PPV), $2 \%$ need intubation to support respiratory function and $0.1 \%$ require chest compressions and/or epinephrine to achieve transitional phase [1-4]. Therefore, delivery room (DR) management

\footnotetext{
* Correspondence: dgazzolo@hotmail.com

${ }^{5}$ Neonatal Intensive Care Unit G. D'Annunzio University of Chieti, Chieti, Italy ${ }^{6}$ Department of Maternal, Fetal and Neonatal Medicine, C. Arrigo Children's Hospital, I-15100 Alessandria, Italy

Full list of author information is available at the end of the article
}

still constitutes a huge challenge for the neonatal team. In this regard, a multidisciplinary approach based on technological, diagnostic, therapeutic and, last but not least, technical (TS) and non-technical skills (NTS) training has been shown to improve DR management [4-8]. NTS, such as team coordination, decision-making, situation awareness and communication, have been previously defined as the cognitive and interpersonal skills that complement an individual's professional and technical knowledge in the facilitation of effective delivery of a safe healthcare system [8-12]. NTS can be implemented through High Fidelity Simulation (HFS)-based training and Crisis Resource Management (CRM) 
training modules. HFS is an educational traning methology characterized by equipment, environmental and psychological high fidelity, the last of which is generally considered the most important for training and learning [13-18].

In the last decade, HFS has been increasingly adopted for clinical training across the medical education continuum [18-25]. The 2015 International Neonatal Resuscitation Guidelines supported HFS as a standard and essential component in neonatal resuscitation training $[2-4,7,13]$, including training practitioners for stress during DR procedures $[25,26]$. Thus, the use of stress and motivation evaluation tests such as the Flow State Scale (FSS) could be of help [25-30]. FFS consists of 36 items divided into 9 subscales, each of which representing a different dimension [31-33]. It is a powerful motivational tool and it is related to skills development [34-41]. At this stage, data evaluating FFS changes during team training in HFS is still lacking.

The purpose of the present study was to investigate study practitioners' flow experiences during in-house HFS courses characterized by progressive complexity. Our hypothesis was that training with HFS would improve the experience of realism for trainees, thus improving motivation and reducing stress in successive training.

\section{Methods}

Between March 2016 and May 2019 we conducted an observational pretest-test study on 43 practitioners admitted to our training center. The characteristics of the recruited subjects are reported in Table 1.

The Neonatal Intensive Care Unit of C. Arrigo Children's Hospital, Alessandria, Italy is the III level Piedmont regional referral centre for neonatal intensive care and for training in neonatal emergency assessment. The neonatal HFS centre of Alessandria has been operating since 2012 within the hub and spoke welfare network. The center also offers HFS courses to other extraregional practitioners.

\section{Neonatal high Fidelity simulation center}

The neonatal HFS centre at C. Arrigo Children's Hospital consists of a scenario room with DR or neonatal intensive care bed, a director's room and classrooms for theoretical lessons and debriefing. The simulation room was modified specifically to have the appearance of a real DR or neonatal intensive care bed. Participants had all the necessary materials for attending to a newborn available, according to the latest American Heart Association (AHA) and Academy of Pediatrics (AAP) recommendations, including: an oxygen-air blender; a T-piece resuscitator $\left(\mathrm{Neo}^{-\mathrm{Te}}{ }^{\bullet}\right.$ Infant $\mathrm{T}$-Piece Resuscitator Mercury Medical, Clearwater, Florida, USA); respiratory
Table 1 General characteristics of practitioners admitted in the study

\begin{tabular}{llll}
\hline Parameter & Data & $\mathbf{N}^{\circ}$ & Percent \\
\hline Gender & Female & 40 & 93 \\
Work Role & Male & 3 & 7 \\
& Nurse & 25 & 58 \\
& Midwife & 7 & 16 \\
& Anesthetist & 2 & 5 \\
& Pediatrician & 8 & 19 \\
Seniority work & Gynecologist & 1 & 2 \\
& $<5$ & 11 & 26 \\
& $5-10$ & 9 & 20 \\
Hospital's Level & $10-20$ & 12 & 28 \\
Previous Course & $>20$ & 11 & 26 \\
Previous HFS Course & II & 17 & 39.5 \\
& Yes & 26 & 60.5 \\
& Yes & 28 & 65 \\
& No & 15 & 35 \\
& & 0 & 0 \\
& No & 43 & 100 \\
\hline
\end{tabular}

support devices for invasive (Leoni Plus, Heinen Lowenstein, Rheinland-Pfalz, Germany) and non invasive (Intant Flow, CareFusion, Hoechberg, Germany) ventilation [2-5].

During scenario performance it was possibile to see the patient's vital signs and laboratory or instrumental tests on a specific monitor. Scenarios were performed by using newborn simulators (SimNewB and Premature Anne, Laerdal Medical Corporation, Laerdal, Stavanger, Norway). SimNewB is highly realistic neonatal simulator with one size and weight of a newborn baby girl delivered at term with approximately $3.5 \mathrm{Kg}$ body weight. Premature Anne is a highly realistic 25 week preterm infant simulator with an approximate weight of $0.6 \mathrm{Kg}$.

A recording system with three high-definition cameras and an ambient microphone located in the resuscitation warmer was used.

\section{HFS courses}

The HFS courses were performed in a time period of 1 month and sub-grouped into two separate sections including theoretical and videos lessons, TS exercises, scenario performances, de-briefings and psychological tests. At the beginning of each section practitioners were grouped into multidisciplinary teams of 3-4 persons (obstetrician, neonatologist, midwife, pediatric nurse) and underwent simulator suite orientation (familiarization).

Sections were characterized by progressive complexity in training, as follows: 


\section{Model 1 (M1)}

The M1 consisted of a 1-day training course (Fig. 1) with theoretical lessons and videos on the following themes: first minute International Newborn Resuscitation Guidelines, AHA and AAP recommendations [2-5]; human error and teamwork simulation-based learning in neonatal resuscitation; NTS; teamwork and European Resuscitation Council (ERC) recommendations for structured multidisciplinary communication. After the theoretical session, practitioners underwent a TS session regarding invasive and non-invasive (stimulation, PPV, intubation) DR resuscitation maneuvers.

TS session was characterized by 3 standardized code scenarios included in the Neonatal Resuscitation Program (NRP) regarding DR resuscitation critical situations. Scenarios were in accordance with standardized models provided by NRP. During practical performance the remaining multidisciplinary teams were able to evaluate the TS procedures via a video-live connection. After practical activities practitioners participated in an video-interactive debriefing session.

\section{Model 2 (M2)}

The M2 consisted of a 1-day training course (Fig. 1) conducted 15 days after M1 with theoretical lessons and videos about the following themes: starting from the second minute International Newborn Resuscitation Guidelines, AHA and AAP recommendations [2-5]; human error and teamwork simulation-based learning in neonatal resuscitation; NTS; teamwork and ERC recommendations for structured multidisciplinary communication. After the theoretical session, practitioners took part in a TS session regarding non-invasive and invasive (chest compressions, drug administration) DR resuscitation maneuvers.

TS session was characterized by 3 standardized code scenarios included in the NRP regarding both $1^{\text {st }}$ and $2^{\text {nd }}$ minute DR resuscitation situations. Scenarios were in accordance with standardized models provided by NRP. During practical performance the other multidisciplinary teams were able to evaluate the TS procedures via a video-live connection. After practical activities, practitioners participated in an interactive videodebriefing session where they can watch themselves during the debriefing session and evaluate, together with the teaching team, the quality of their performance.

The teaching team was formed of 8 expert trainers (neonatologists: $n=4$; pediatric nurses: $n=4$ ) in simulation, debriefing, teamwork and communication, certified by the Italian Society of Neonatology (SIN).

\section{Flow state scale}

The FSS test was administered to practitioners at the end of M1 and M2 scenario, respectively. The FSS consists of 36 items divided into 9 subscales, the short flow scale (SFSS), each representing the nine different dimensions of Flow (Tables 2, 3). These nine dimensions are: challenge-skill balance, action-awareness merging, clear goals, unambiguous feedback, concentration on task, sense of control, loss of self-consciousness, time

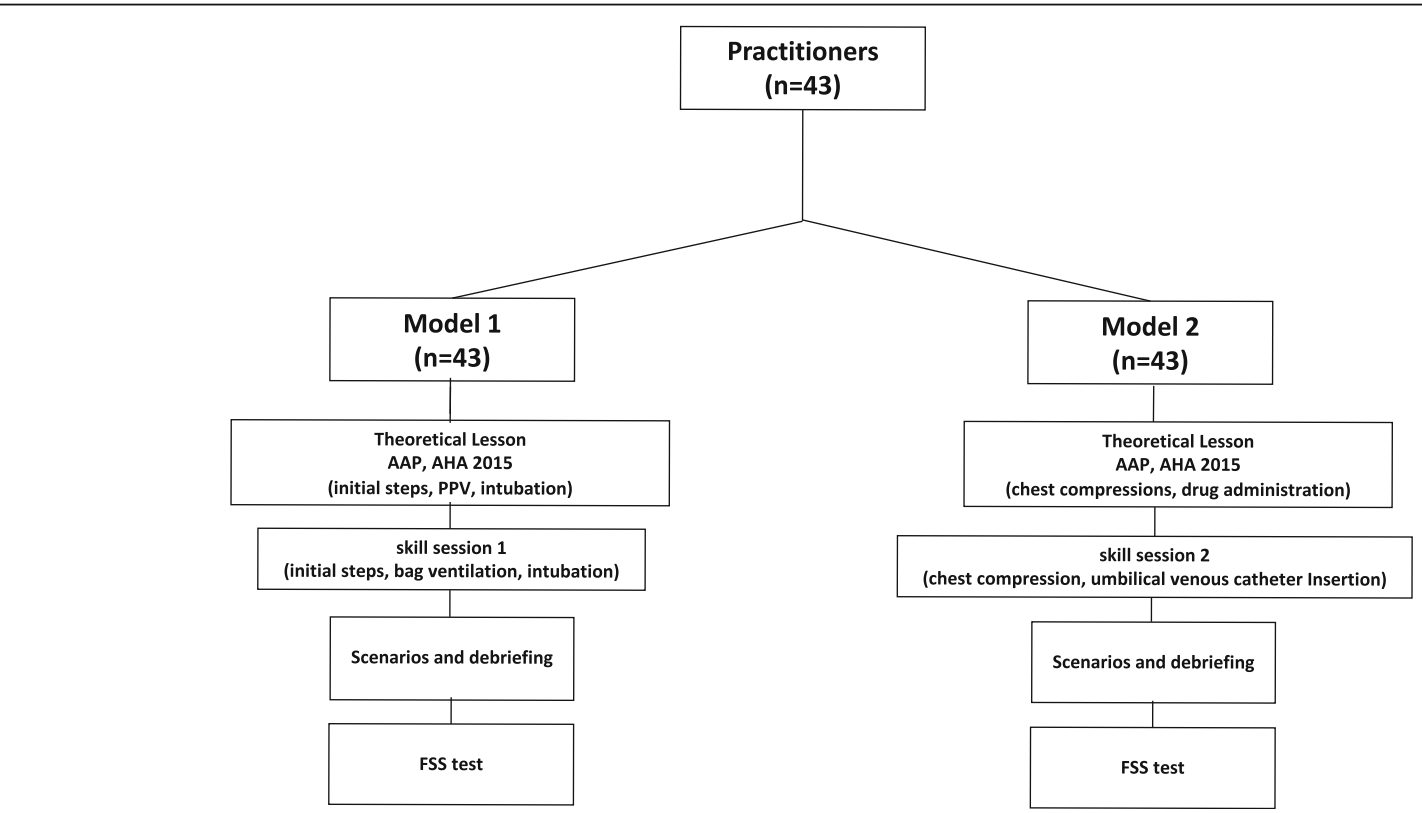

Fig. 1 Flow-chart of the training program according to the American Academy of Pediatrics (AAP) and American Heart Association (AHA) neonatal resuscitaton statements. Flow State Scale (FSS) test was administrated to practiotioners at the completion of every training model 
Table 2 Flow state scale test items (Pi) results recorded at the end of Model $1(\mathrm{M} 1)$ and Model 2 (M2) high fidelity simulation scenarios in the 43 trainees admitted in the study

\begin{tabular}{|c|c|c|c|c|c|c|c|c|}
\hline \multirow[t]{2}{*}{$\overline{\mathrm{Pi}}$} & \multirow[t]{2}{*}{ Description } & \multicolumn{3}{|c|}{ M1 $(n=43)$} & \multicolumn{3}{|c|}{ M2 $(n=43)$} & \multirow[t]{2}{*}{$P$} \\
\hline & & Median & $\begin{array}{l}25^{\circ} \\
\text { centile }\end{array}$ & $\begin{array}{l}75^{\circ} \\
\text { centile }\end{array}$ & Median & $\begin{array}{l}25^{\circ} \\
\text { centile }\end{array}$ & $\begin{array}{l}75^{\circ} \\
\text { centile }\end{array}$ & \\
\hline 1 & $\begin{array}{l}\text { I am challenged, but I believe my skills will allow me to meet the } \\
\text { challenge }\end{array}$ & 3.00 & 3.00 & 3.00 & 3.00 & 3.00 & 3.00 & 0,928 \\
\hline 2 & make the correct movements without thinking about trying to do so & 3.00 & 2.00 & 3.00 & 3.00 & 2,00 & 3.00 & 0,111 \\
\hline 3 & I know clearly what I want to do & 3.00 & 3.00 & 4.00 & 3.00 & 3,00 & 4.00 & 0,832 \\
\hline 4 & It is really clear to me how my performance is going & 3.00 & 2.00 & 3.00 & 3.00 & 3,00 & 3.75 & 0,038 \\
\hline 5 & My attention is focused entirely on what I am doing & 4.00 & 3.00 & 3.00 & 4.00 & 4.00 & 5.00 & 0,060 \\
\hline 6 & I have a sense of control over what I am doing & 3.00 & 3.00 & 3.75 & 3.00 & 3.00 & 3.00 & 0,444 \\
\hline 7 & I am not concerned with what others may be thinking of me & 3.00 & 2.00 & 3.00 & 3.00 & 2.00 & 4.00 & 0,007 \\
\hline 8 & Time seems to alter (either slows down or speeds up) & 4.00 & 2.00 & 4.00 & 3.00 & 2.25 & 4.00 & 0,789 \\
\hline 9 & I really enjoy the experience & 4.00 & 3.00 & 4.00 & 4.00 & 3.00 & 4.00 & 0,522 \\
\hline 10 & My abilities match the high challenge of the situation & 3.00 & 3.00 & 3.00 & 3.00 & 3.00 & 4.00 & 0,330 \\
\hline 11 & Things just seem to happen automatically & 3.00 & 3.00 & 3.00 & 3.00 & 3.00 & 4.00 & 0,051 \\
\hline 12 & I have a strong sense of what I want to do & 3.00 & 3.00 & 3.00 & 4.00 & 3.00 & 4.00 & 0,270 \\
\hline 13 & I am aware of how well I am performing & 3.00 & 2.00 & 3.00 & 3.00 & 2.25 & 3.00 & 0,039 \\
\hline 14 & It is no effort to keep my mind on what is happening & 3.00 & 3.00 & 4.00 & 4.00 & 3.00 & 4.00 & 0,057 \\
\hline 15 & I feel like I can control what I am doing & 3.00 & 3.00 & 3.00 & 3.00 & 3.00 & 3.00 & 0,146 \\
\hline 16 & I am not concerned with how others may be evaluating me & 3.00 & 2.00 & 3.00 & 3.00 & 3.00 & 4.00 & 0,058 \\
\hline 17 & The way time passes seems to be different from normal & 4.00 & 3.00 & 4.00 & 3.00 & 3.00 & 4.00 & 0,736 \\
\hline 18 & I love the feeling of the performance and want to capture it again & 3.00 & 3.00 & 4.00 & 3.00 & 3.00 & 4.00 & 0,802 \\
\hline 19 & $\begin{array}{l}\text { I feel I am competent enough to meet the high demands of the } \\
\text { situation }\end{array}$ & 3.00 & 3.00 & 3.00 & 3.00 & 3.00 & 3.00 & 0,710 \\
\hline 20 & I perform automatically, without thinking too much & 3.00 & 2.25 & 4.00 & 3.00 & 3.00 & 4.00 & 0,385 \\
\hline 21 & I know what I want to achieve & 3.00 & 3.00 & 4.00 & 4.00 & 3.00 & 4.00 & 0,503 \\
\hline 22 & $\begin{array}{l}\text { I have a good idea while I am performing about how well I am } \\
\text { doing }\end{array}$ & 3.00 & 3.00 & 3.00 & 3.00 & 3.00 & 3.00 & 0,610 \\
\hline 23 & I have total concentration & 4.00 & 3.00 & 4.00 & 4.00 & 3.00 & 4.00 & 0,333 \\
\hline 24 & I have a feeling of total control & 3.00 & 2.25 & 3.00 & 3.00 & 3.00 & 3.00 & 0,228 \\
\hline 25 & I am not concerned with how I am presenting myself & 3.00 & 2.00 & 3.00 & 3.00 & 2.25 & 4.00 & 0,014 \\
\hline 26 & It feels like time goes by quickly & 3.00 & 1.25 & 4.00 & 3.00 & 2.00 & 4.00 & 0,042 \\
\hline 27 & The experience leaves me feeling great & 3.00 & 3.00 & 4.00 & 4.00 & 3.00 & 4.00 & 0,093 \\
\hline 28 & The challenge and my skills are at an equally high level & 3.00 & 3.00 & 3.00 & 3.00 & 3.00 & 3.00 & 0,339 \\
\hline 29 & I do things spontaneously and automatically without having to think & 3.00 & 2.25 & 3.00 & 3.00 & 3.00 & 4.00 & 0,148 \\
\hline 30 & My goals are clearly defined & 4.00 & 3.00 & 4.00 & 4.00 & 3.00 & 4.00 & 0.836 \\
\hline 31 & I can tell by the way I am performing how well I am doing & 3.00 & 2.00 & 3.00 & 3.00 & 3.00 & 3.00 & 0.170 \\
\hline 32 & I am completely focused on the task at hand & 4.00 & 3.00 & 4.00 & 4.00 & 3.00 & 4.00 & 0.713 \\
\hline 33 & I feel in total control of my body & 3.00 & 3.00 & 4.00 & 3.00 & 3.00 & 4.00 & 0.931 \\
\hline 34 & I am not worried about what others may be thinking of me & 3.00 & 2.00 & 3.00 & 3.00 & 2.00 & 4.00 & 0.018 \\
\hline 35 & I lose my normal awareness of time & 3.00 & 2.00 & 3.00 & 3.00 & 2.25 & 4.00 & 0.029 \\
\hline 36 & The experience is extremely rewarding & 3.00 & 3.00 & 4.00 & 4.00 & 3.00 & 4.00 & 0.308 \\
\hline
\end{tabular}

transformation, and autotelic experience. Considered together, these dimensions represent the optimal psychological state of flow; singly they signify conceptual elements of this state (Table 3). The 36 items (Pi) also contribute to a broad second-order general flow factor (Table 2). Participants were asked to answer all 36 items 
Table 3 Short Flow State Scale (SFSS) results recorded at the end of Model 1 (M1) and Model 2 (M2) high fidelity simulation scenarios in the 43 trainees admitted in the study

\begin{tabular}{|c|c|c|c|c|c|c|c|c|c|}
\hline \multicolumn{10}{|c|}{ Short Flow Flow State Scale - Subscale dimension } \\
\hline \multirow[b]{2}{*}{ SFSS } & & \multirow[t]{2}{*}{ Items } & \multicolumn{3}{|c|}{$M 1(n=43)$} & \multicolumn{3}{|c|}{ M2 $(n=43)$} & \multirow[t]{2}{*}{$\mathbf{P}$} \\
\hline & & & median & $25^{\circ}$ & $75^{\circ}$ & median & $25^{\circ}$ & $75^{\circ}$ & \\
\hline 1 & Challenge-Skill Balance & $\mathrm{Pi} 1+\mathrm{Pi} 10+\mathrm{Pi} 19+\mathrm{Pi} 28$ & 12.00 & 11.00 & 13.00 & 12,00 & 12.00 & 14.00 & 0.53 \\
\hline 2 & Merging of Action and Awareness & $\mathrm{Pi} 2+\mathrm{Pi} 11+\mathrm{Pi} 20+\mathrm{Pi} 29$ & 12.00 & 10.00 & 13.00 & 13.00 & 11.00 & 14.00 & 0.04 \\
\hline 3 & Clear Goals & $\mathrm{Pi}+\mathrm{Pi} 12+\mathrm{Pi} 21+\mathrm{Pi} 30$ & 13.00 & 12.00 & 15.00 & 14,00 & 12.25 & 15.00 & 0.37 \\
\hline 4 & Unambiguous Feedback & $\mathrm{Pi} 4+\mathrm{Pi} 13+\mathrm{Pi} 22+\mathrm{Pi} 31$ & 12.00 & 9.25 & 13.00 & 12.00 & 11.00 & 14.00 & 0.04 \\
\hline 5 & Concentration on the Task at Hand & $\mathrm{Pi} 5+\mathrm{Pi} 14+\mathrm{Pi} 23+\mathrm{Pi} 32$ & 15.00 & 13.00 & 16.00 & 15,00 & 14.00 & 17.00 & 0.06 \\
\hline 6 & Sense of Control & $\mathrm{Pi} 6+\mathrm{Pi} 15+\mathrm{Pi} 24+\mathrm{Pi} 33$ & 12.00 & 11.00 & 13.00 & 12.00 & 12.00 & 14.00 & 0.13 \\
\hline 7 & Loss of Self-Consciousness & $\mathrm{Pi} 7+\mathrm{Pi} 16+\mathrm{Pi} 25+\mathrm{Pi} 34$ & 11.00 & 08.00 & 12.00 & 13.00 & 9.50 & 15.00 & 0.002 \\
\hline 8 & Transformation of Time & $\mathrm{Pi} 8+\mathrm{Pi} 17+\mathrm{Pi} 26$ + Pi35 & 11.74 & 10.00 & 13.00 & 13.09 & 12.40 & 14.00 & 0.11 \\
\hline 9 & Autotelic Experience & $\mathrm{Pi} 9+\mathrm{Pi} 18+\mathrm{Pi} 27+\mathrm{Pi} 36$ & 13.90 & 12.80 & 14.90 & 14.60 & 13.40 & 15.50 & 0.26 \\
\hline
\end{tabular}

Abbreviation: flow state scale item $(\mathrm{Pi})$

after scenario session. Each item was scored from 1 to 5 as follows: never, 1; rarely, 2; sometimes, 3; frequently, 4; always 5 .

The study protocol was approved by the local Ethics Committee (ASO.neonat.00022886) and the subjects examined gave informed and signed consent.

\section{Statistical analysis}

For sample size calculation, we used changes in FFS as the main parameter [25]. We assumed an increase of 0.5 $\mathrm{SD}$ in FFS to be clinically significant. Considering an $\alpha=$ 0.05 and using a two-sided test, we estimated a power of 0.90 , recruiting 41 practitioners. We added $n=2$ cases to allow for dropouts and consent not given. The study population was therefore composed of 43 practitioners who underwent M1 and M2 training sections (Fig. 1). FFS values were expressed as median and $25-75^{\text {th }}$ centiles. Data were analyzed by Kruskal-Wallis one-way analysis of variance and Mann-Whitney $U$ test when not normally distributed. Statistical significance was set at $P<0.05$.

\section{Results}

In Table 1 the characteristics of the practitioners admitted to the study are reported. Higher female $(P<0.001)$ incidence was observed when study group was corrected for gender. As expected, in term of the role of the recruited practitioners the incidence of nurses participating in M1 and M2 models was significantly $(P<0.05)$ higher than for other practitioners. Moreover, the number of obstetricians and anesthetists participating was significantly lower $(P<0.01)$ than for other disciplines (midwives, pediatricians/neonatologists, nurses). No significant differences $(P>0.05$, for all $)$ in terms of seniority were observed among different categories. Of note, the number of practitioners coming from I-II hospital levels was significantly lower $(\mathrm{P}<0.05)$ than those coming from III level referral centres. Twenty-eight out of 43 practitioners had previously experienced resuscitation courses but none of them HFS courses.

In Table 2 the characteristics of the 36 FSS items are reported. No significant $(\mathrm{P}>0.05$, for all) statistical differences have been found between the two training sections regarding 29 out of 36 FFS items (Pi1-Pi3; Pi5, Pi6; Pi8-12; Pi14-Pi24; Pi27-Pi33; Pi36, respectively). Conversely, higher Pi4 (it was really clear to me how my performance was going), Pi7 (I was not concerned about what others might be thinking of me), Pi13 (I was aware of how well I was performing), Pi25 (I was not concerned about how I was presenting myself), Pi26 (it felt that time went by quickly), Pi34 (I was not worried about what others might be thinking of me) and, Pi35 (I lost my normal awareness of time) were observed in the studied group at the end of M2 performance.

In Table 3 the SFSS characteristics at M1 and M2 are reported. No significant differences have been found between M1 and M2 regarding SFSS1, SFSS5, SFSS6, SFSS8 and SFSS9, respectively. Conversely, higher $(P<$ 0.05 , for all) SFSS values at M2 than M1 were found regarding SFSS2 (merging of action and awareness), SFSS4 (unambiguous feed-back), and SFSS7 (loss of selfconsciousness).

\section{Discussion}

Approximately $10 \%$ of all newborns require resuscitation at birth [1-4]. Training healthcare providers in standardised formal neonatal resuscitation training programmes may improve neonatal outcomes [4-8]. However, despite a reduction of early neonatal and 28-day mortality further trials are required to enable a significant decline in the incidence of neonatal morbidity, including hypoxic ischaemic encephalopathy and neurodevelopmental 
outcomes. Therefore, innovative educational methods able to enhance knowledge, skills and teamwork behaviour are eagerly sought [4-8]. In this regard, there is growing evidence that DR management by a multidisciplinary team can be ameliorated by HFS team training [15-18]. HFS can improve knowledge, behaviour and practice through training in new techniques focused on experiential learning [16-18]. However, data on the effectiveness of HFS on stress-training of practitioners are still needed.

In the present study we found that in a cohort of practitioners taking part in HFS scenarios of progressive severity in DR resuscitation management, the administration of a well-established attitudinal test of stressevent management, namely FSS, showed significant improvement from M1 to M2 in 7 out of 36 FSS items. Furthermore, when FSS results were subgrouped into nine subscales expression of self-consciousness during emergency experience, a significant improvement was observed in three out of the nine analyzed.

The findings partly match previous observations in HFS pediatric programs. The discrepancy lies in terms of teaching program topics (pediatrics vs neonatologists) and scenarios (septic shock and severe asma vs DR resuscitation) [25]. Another explanation lies in the technical and timing of TS performances (2 sessions of 90 min vs one-day M1 and M2 models).

The findings of a significant increase in 7 out $36 \mathrm{Pi}$ items between $\mathrm{M} 1$ and $\mathrm{M} 2$ warrant further consideration. In particular, taken singly they are the expression of several psychological aspects met during HFS training such as: i) the practitioners' involvement in scenario performance in terms of familiarization with the training room, the awareness of what they need to do in scenario management (Pi4) and the consciousness of the efficacy of their DR management and resuscitation maneuvers (Pi13), ii) the intensity of practitioners' involvement in scenario performance characterized by the absence of any psychological inhibition due to external evaluators and observers (Pi7, Pi25). In particular, they were not worried by or they do not care about audience judgment of their DR management (Pi34), and iii) the loss of time dimension that differed among practitioners in terms of duration quickly (Pi26) or loss (Pi35). The present patterns are in line with those detected in other activities at high risk for performance under stress such as intensivists, athletes and firefighters [25-29, 36-39, 42-45]. Altogether, the aforementioned results are reasonably supportive of the effectiveness of HFS training in terms of the fidelity of the scenarios to real life. The findings were furthermore corroborated by all practitioners, who during the debriefing phase, confirmed their feeling that after a few seconds from DR maneuvers starting they were supporting a newborn and not a simulator.
In the present study we also found that short dispositional flow scale items herein called SFSS significantly increased from M1 to M2. In particular, the combination of $\mathrm{Pi}$ items provided evidence that all the practitioners showed: i) a clear idea (SFSS2, SFSS4) of the stabilization and resuscitation procedures that needed to be performed in order to guarantee the best support to the newborn in DR, and ii) the highest level of focus on reaching the target (i.e. newborn safety). Results are in line with those detected in other activities at high risk for performance under stress such as intensivists, professional sportsmen and firefighters [37-49]. Altogether, it is reasonable to conclude that HFS training not only provides an enhancement of the awareness of the quality of NTS and TS performance but also the psychological involvement that is commonly met in real-assistance of high risk newborns.

Lastly, we recognize that the present study has several limitations. In particular: i) the evaluation of the impact of HFS training on clinical practice is today still the object of debate, ii) the need to correlate the level of psychological stress, during scenario performance, with new experimental video-computerized programs able to offer a qualitative and quantitative evaluation of DR management as for other NICU maneuvers [50]. In this light investigations over a wider study-population are required.

\section{Conclusions}

In conclusion, the present results showing the high level of practitioners involvement during DR management simulations offer additional support to the usefulness of HFS as a trustworthy tool for improving the awareness of NTS and TS performance in neonatal care. The data open the way for further investigations aimed at the evaluation not only of individual but also of muldisciplinary team performances.

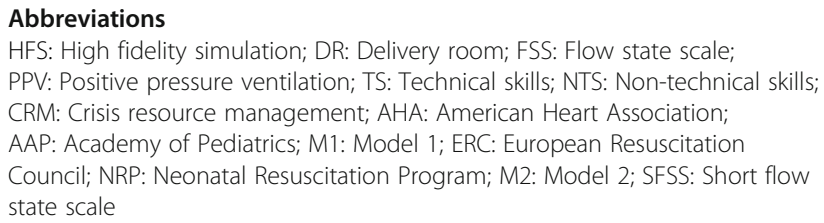

\section{Acknowledgments}

This work is part of the I.O. PhD International Program under the auspices of the Italian Society of Neonatology and was partially supported by grants to DG from "I Colori della Vita Foundation", Italy.

\section{Authors' contributions}

Mariachiara Strozzi and Alessandro Varrica contributed to conceptualization, investigation, writing - original draft. Micaela Colivicchi contributed to conceptualization, investigation, writing - review and editing. Claudia Pelazzo, Rossana Negri, Anna Galante, Patrizia lanniello, Rossella Sterpone, Priscilla Nannini, Daniela Leo, Manuel Striani, Stefania Montani contributed to investigation and conceptualization. Diego Gazzolo contributed to project administration, conceptualization, investigation, supervision, writing - review and editing. All authors approved the final manuscript as submitted and agree to be accountable for all aspects of the work. 


\section{Funding}

This work is part of the I.O. PhD International Program under the auspices of the Italian Society of Neonatology and was partially supported by grants to DG from "I Colori della Vita Foundation", Italy.

\section{Availability of data and materials}

The data will not be shared to respect the privacy of the participants.

\section{Ethics approval and consent to participate}

The study was approved the local Ethics Committee (ASO.neonat.00022886).

\section{Consent for publication}

The subjects examined gave informed and signed consent.

\section{Competing interests}

The funding organizations played no role in the study design; in the collection, analysis, and interpretation of data; in the writing of the report; or in the decision to submit the report for publication.

\section{Author details}

${ }^{1}$ Neonatal Intensive Care Unit AO S.S. Antonio, Biagio and C. Arrigo Hospital, Alessandria, Italy. ${ }^{2}$ Department of Paediatric Cardiovascular Surgery, Laboratory Research, San Donato Milanese University Hospital, San Donato, Italy. ${ }^{3}$ Psychology Unit AO S.S. Antonio, Biagio and C. Arrigo Hospital, Alessandria, Italy. ${ }^{4}$ Science and Technological Innovation Department, University of Piemonte Orientale, Alessandria, Italy. ${ }^{5}$ Neonatal Intensive Care Unit G. D'Annunzio University of Chieti, Chieti, Italy. ${ }^{6}$ Department of Maternal, Fetal and Neonatal Medicine, C. Arrigo Children's Hospital, I-15100 Alessandria, Italy.

\section{Received: 30 May 2020 Accepted: 21 January 2021}

\section{Published online: 25 February 2021}

\section{References}

1. Ersdal HL, Mduma E, Svensen E, Perlman JM. Early initiation of basic resuscitation interventions including face mask ventilation may reduce birth asphyxia related mortality in low-income countries: a prospective descriptive observational study. Resuscitation. 2012;83:869-87.

2. Wyckoff MH, Aziz K, Escobedo MB, Kapadia VS, Kattwinkel J, Perlman JM, et al. Part 13: neonatal resuscitation: 2015 American Heart Association guidelines update for cardiopulmonary resuscitation and emergency cardiovascular care. Circulation. 2015;132:S543-60.

3. Perlman JM, Wyllie J, Kattwinkel J, Wyckoff MH, Aziz K, Guinsburg R, et al. Part 7: neonatal resuscitation: 2015 international consensus on cardiopulmonary resuscitation and emergency cardiovascular care science with treatment recommendations. Circulation. 2015;132:S204-41.

4. Weiner GM, Delfino A, editors. Textbook of Neonatal Resuscitation. 7th ed. American Academy of Pediatrics: Florence; 2016.

5. Thomas EJ, Williams AL, Reichman EF, Lasky RE, Crandell S, Taggart WR. Team training in the neonatal resuscitation program for interns: teamwork and quality of resuscitations. Pediatrics. 2010;125:539-46.

6. Halamek LP, Kaegi DM, Gaba DM, Sowb YA, Smith BC, Smith BE, Howard SK Time for a new paradigm in pediatric medical education: teaching neonatal resuscitation in a simulated delivery room environment. Pediatrics. 2000;106: E45-51.

7. Ades A, Lee HC. Update on simulation for the neonatal resuscitation program. Semin Perinatol. 2016;40:447-54.

8. Pammi M, Dempsey MD, Ryan CA, Barrington KJ. Newborn resuscitation training programmes reduce early neonatal mortality. Neonatology. 2016; 110:210-24.

9. Kohn LT, Corrigan J, Donaldson MS. To Err Is Human: Building A Safer Health System. Washington (DC): National Academies Press; 2000.

10. The Joint Commission: Sentinel event alert, Issue 30. Preventing infant death and injury during delivery; 1995-2004 Washington (DC): Joint Commission on Accreditation of Healthcare Organizations. 2004.

11. Manser T. Teamwork and patient safety in dynamic domains of healthcare: a review of the literature. Acta Anaesthesiol Scand. 2009:53:143-51.

12. Dempsey E, Pammi M, Ryan AC, Barrington KJ. Standardised formal resuscitation training programmes for reducing mortality and morbidity in newborn infants. Cochrane Database Syst Rev. 2015;9:CD009106.
13. Arnold J. Neonatal resuscitation program comes of age. J Pediatr. 2011;159: 357-8.

14. O'Currain E, Davis PG, Thio M. Educational perspectives: toward more effective neonatal resuscitation: assessing and improving clinical skills. Neoreviews. 2019;20:e248-57.

15. Murphy A, Halamek L. Simulation-based training in neonatal resuscitation. Neoreviews. 2005;11:e489-91.

16. Rakshasbhuvankar AA, Patole SK. Benefits of simulation based training for neonatal resuscitation education: a systematic review. Resuscitation. 2014;85 1320-3.

17. Rubio-Gurung S, Putet G, Touzet S, Gauthier-Moulinier H, Jordan I, Beissel A, et al. In situ simulation training for neonatal resuscitation: an RCT. Pediatrics. 2014;134:e790-7.

18. Huang J, Tang $Y$, Tang J, Shi J, Wang H, Xiong $T$, et al. Educational efficacy of high-fidelity simulation in neonatal resuscitation training: a systematic review and meta-analysis. BMC Med Educ. 2019;19:323-33.

19. Weis JJ, Croft CL, Bhoja R, Lee JH, Scott DJ. Multidisciplinary simulation activity effectively prepares residents for participation in patient safety activities. J Surg Educ. 2019:76:e232-7.

20. Cheng A, Lockey A, Bhanji F, Lin Y, Hunt EA, Lang E. The use of high-fidelity manikins for advanced life support training--a systematic review and metaanalysis. Resuscitation. 2015;93:142-9.

21. Crofts J, Bartlett C, Ellis D, Hunt L, Fox R, Draycott T. Training for shoulder dystocia: a trial of simulation using low-fidelity and high-fidelity mannequins. Obstet Gynecol. 2006;108:1477-85.

22. Jackson KS. The importance of non-technical skills and risk reduction in the operating theatre. Obstetrician Gynaecol. 2016;18:309-14

23. Kunzle B, Zala-Mezo E, Wacker J, Kolbe M, Spahn DR, Grote G. Leadership in anaesthesia teams: the most effective leadership is shared. Qual Saf Health Care. 2010;19:1-6.

24. Flin R, Maran N. Basic concepts for crew resource management and nontechnical skills. Best Pract Res Clin Anaesthesiol. 2015;29:27-39.

25. Meurling L, Hedman L, Lidefelt KJ, Escher C, Felländer-Tsai L, Wallin CJ. Comparison of high- and low equipment fidelity during paediatric simulation team training: a case control study. BMC Med Educ. 2014;14 221-8.

26. Lizotte $\mathrm{MH}$, Janvier A, Latraverse V, Lachance C, Walker CD, Barrington KJ, Moussa A. The impact of neonatal simulations on Trainees' stress and performance: a parallel-group randomized trial. Pediatr Crit Care Med. 2017; 18:434-41.

27. Krage R, Zwaan L, Tjon Soei Len L, Kolenbrander MW, van Groeningen D, Loer SA, et al. Relationship between non-technical skills and technical performance during cardiopulmonary resuscitation: does stress have an influence? Emerg Med J. 2017;34:728-33.

28. Judd BK, Currie J, Dodds KL, Fethney J, Gordon CJ. Registered nurses psychophysiological stress and confidence during high-fidelity emergency simulation: effects on performance. Nurse Educ Today. 2019;78:44-9.

29. Geeraerts T, Roulleau P, Cheisson G, Marhar F, Aidan K, Lallali K, et al. Physiological and self-assessed psychological stress induced by a high fidelity simulation course among third year anesthesia and critical care residents: an observational study. Anaesth Crit Care Pain Med. 2017;36: 403-6.

30. Koehn S. Effects of confidence and anxiety on flow state in competition. Eur J of Sport Sci. 2013;13:543-50.

31. Nakamura J, Csikszentmihalyi M. The concept of flow. Flow and the Foundation of Positive Psychology; 2014. p. 239-63.

32. Jackson SA, Marsh HW. Development and validation of a scale to measure optimal experience: the flow state scale. J Sport Exercise Psychol. 1996;18: $17-35$.

33. Jackson S, Martin AJ, Eklund RC. Long and short measures of flow: the construct validity of the FSS-2. DFS-2, and new brief counterparts. J Sport Exerc Psychol. 2008;30:561-87.

34. Csikszentmihalyi M, LeFevre J. Optimal experience in work and leisure. J Pers Soc Psychol. 1989;56:815-22.

35. Edmondson A. Psychological safety and learning behavior in work teams. Adm Sci O 1999:44:350-83.

36. Anderson DR, Crous AF, Schepers JM. Flow and quality of work life in a diverse workforce. J Indust Psychol. 1996;22:13-20.

37. Engeser S, Rheinberg F. Flow, performance and moderators of challengeskill balance Motiv Emot. 2008:32:158-72. 
38. DeLaVega R, Pérez García J, Ruiz-Barquín R, Marquez S. Flow in firefighters and its relationship with performance in high-risk tasks: preliminar research. Psychologia. 2015;58:167-75.

39. Salanova M, Bakker AB, Llorensm S. Flow at work: evidence for an upward spiral of personal and organizational resources. J Happiness Stud. 2006;7:122

40. Fullagar CJ, Kelloway EK. Flow at work: an experience sampling approach. J Occup Organ Psychol. 2009:82:595-615.

41. van den Hout JJ, Davis OC. Team flow: the psychology of optimal collaboration. SpringerBriefs in well-being and quality of life research. Springer Nature Social Sciences Chapter 3. Senior Publishing Editor; 2019. p. 1-136.

42. Jackson SA. Factors influencing the occurrence of flow state in elite athletes. J Appl Sport Psychol. 1995;7:138-66.

43. Koehn $\mathrm{S}$, Morris $\mathrm{T}$. The relationship between performance and flow state in tennis competition. J Sports Med Phys Fitness. 2012;52:1-11.

44. Jackson SA, Thomas PR, Marsh HW, Smethurst CJ. Relationships between flow, self-concept, psychological skills, and performance. J Appl Sport Psychol. 2001;13:129-53.

45. Stavrou NA, Zervas Y, Karteroliotis K, Jackson SA. Flow experience and athletes' performance with reference to the orthogonal model of flow. Sport Psychol. 2007:21:438-57.

46. van den Hout JJ, Davisb OC, Weggeman M. The conceptualization of team flow. J Psychol. 2018;152:388-423.

47. Mannella P, Palla G, Cuttano A, Boldrini A, Simoncini T. Effect of high-fidelity shoulder dystocia simulation on emergency obstetric skills and crew resource management skills among residents. Int J Gynaecol Obstet. 2016; 135:338-42.

48. Bracco F, de Tonetti G, Masini M, Passarelli M, Geretto F, Celleno D. Crisis resource Management in the Delivery Room: development of behavioral markers for team performance in emergency simulation. Int I Environ Res Public Health. 2018;15:439-49.

49. Dadiz R, Weinschreider J, Schriefer J, Arnold C, Greves CD, Crosby EC, Wang H, Pressman EK, Guillet R. Interdisciplinary simulation-based training to improve delivery room communication. Simul Healthc. 2013;8:279-91.

50. Montani S, Canonico M, Gazzolo D, Strozzi MC, Striani M. TEEM: technologyenhanced emergency Management for Supporting Data Communication during Patient Transportation. Int J Mob Comp Mult Comm. 2017;8:49-65.

\section{Publisher's Note}

Springer Nature remains neutral with regard to jurisdictional claims in published maps and institutional affiliations.

Ready to submit your research? Choose BMC and benefit from:

- fast, convenient online submission

- thorough peer review by experienced researchers in your field

- rapid publication on acceptance

- support for research data, including large and complex data types

- gold Open Access which fosters wider collaboration and increased citations

- maximum visibility for your research: over $100 \mathrm{M}$ website views per year

At $\mathrm{BMC}$, research is always in progress.

Learn more biomedcentral.com/submissions 